\title{
O PENSAMENTO CATÓLICO NO CONTEXTO DOS EMBATES POLÍTICOS DA DÉCADA DE 1930 NO BRASIL
}

\author{
EL PENSAMIENTO CATÓLICO EN EL CONTEXTO DE LOS EMBATES \\ POLÍTICOS DE LA DÉCADA DE 1930 EN BRASIL
}

\author{
THE CATHOLIC THOUGHT IN THE CONTEXT OF POLITICAL CLASHES OF \\ 1930S IN BRAZIL
}

\author{
Aline Christine de SOUZA ${ }^{1}$ \\ José Luis DERISSo ${ }^{2}$
}

RESUMO: A produção deste artigo decorre de estudos realizados no âmbito de uma pesquisa de iniciação científica cujo objeto é o pensamento católico no Brasil no contexto dos embates com os chamados "Pioneiros da Educação Nova", que antecederam a elaboração da Constituição de 1934. Trata-se de uma pesquisa bibliográfica que priorizou o estudo, por um lado, dos fundamentos do pensamento católico em documentos eclesiásticos e, por outro, de sua manifestação no Brasil por meio da revista $A$ Ordem, sua principal expressão pública. Conclui-se que o pensamento católico constitui importante ingrediente ideológico do contexto em questão e se desenvolve em consonância com a luta de classes na Europa e das frações da classe dominante no Brasil, expressando a resistência da Igreja Católica ao modelo republicano de escola e ao ideal, também republicano, da laicidade do Estado.

PALAVRAS CHAVE: Pensamento católico. Constituição de 1934. Brasil. Educação.

RESUMEN: La producción de este artículo se deriva de estudios realizados en el marco de una investigación de iniciación científica cuyo objeto es el pensamiento católico en Brasil en el contexto de los embates con los llamados "Pioneros de la Educación Nueva", que precedieron a la elaboración de la Constitución de 1934. Se trata de una investigación bibliográfica que priorizó el estudio, por un lado, de los fundamentos del pensamiento católico en documentos eclesiásticos y, por otro, de su manifestación en Brasil por medio de la revista A Orden, su principal expresión pública. Se concluye que el pensamiento católico constituye un importante ingrediente ideológico del contexto en cuestión y se desarrolla en consonancia con la lucha de clases en Europa y de las fracciones de la clase dominante en Brasil, expresando la resistencia de la Iglesia Católica al modelo republicano de escuela y al ideal, también republicano, de la laicidad del Estado.

\footnotetext{
${ }^{1}$ Universidade Estadual do Oeste do Paraná (Unioeste), Cascável - PR - Brasil. Graduanda do curso de Pedagogia. Bolsista de Iniciação Científica do CNPq. E-mail: apedm1 @ gmail.com.

${ }^{2}$ Universidade Estadual do Oeste do Paraná (Unioeste), Cascável - PR - Brasil. Professor Adjunto de Fundamentos da Educação. Doutor em Educação Escolar. Membro do Grupo de Estudos e Pesquisas em "História, Sociedade e Educação no Brasil" - GT da Região Oeste doParaná - "HISTEDOPR"; E-mail: joseluisderisso@yahoo.com.br.
} 
PALABRAS CLAVE: Pensamiento católico. Constituición de 1934. Brasil. Educación.

ABSTRACT: The production of this article results from studies realized in the scope of a research of scientific initiation which the object is the Catholic Thought in Brazil in the context of the clashes with the so-called "Pioneers of New Education" that preceded the elaboration of the Constitution of 1934. It is a bibliographic research that prioritized the study, on the one hand, of the fundamentals of Catholic Thought in ecclesiastic documents and, on the other hand, of its manifestation in Brazil through "A Ordem" magazine, its mainly public expression. It is concluded that the Catholic Thought constitute an important ideological ingredient in the context in question and develops in accord with the class struggle in Europe and the fractions of the dominant class in Brazil, expressing the resistance of the Catholic Church to the republican model of school and to the ideal, also republican, of State secularism.

KEYWORDS: Catholic thought. Constitution of 1934. Brazil. Education.

\section{Introdução}

Nos dezoito anos que separam a chamada "Questão Religiosa do Império", na década de 1870, até a proclamação da República brasileira, em 1888, a relação entre política e religião deteriorou-se a passos largos, levando à abolição do regime do padroado régio e à radical separação entre Estado e Igreja.

No século XIX, a Igreja Católica sustentou um conjunto de posições frontalmente contrárias às transformações políticas que se operaram desde o início do processo de revoluções burguesas iniciada pela Revolução Francesa de 1789 e do surgimento do movimento operário organizado iniciado como movimento cartista na Inglaterra em 1837. Tais posições foram expressas num conjunto de encíclicas por meio das quais a Santa Sé condenava a maçonaria, a democracia representativa, a laicidade do Estado e da Educação, o modernismo e o comunismo, entre outros.

No Brasil, após a Proclamação da República, a Igreja dizia-se favorável ao regime de separação entre política e religião, mas disputava espaços institucionais e combatia a laicidade do Estado e mais particularmente da Educação. Tal perspectiva se manifesta no processo de elaboração da Constituição de 1934 e nos embates políticos e ideológicos que a antecedem, por meio da defesa de medidas constitucionais que combatiam a laicidade, o modelo republicano de escola e o divórcio, entre outras. Para tanto, a cúpula da Igreja Católica no Brasil articula a Liga Eleitoral Católica (LEC) e se apoia na atividade propagandística de uma 
intelectualidade católica leiga que se organizava no Centro D. Vital e se expressava, principalmente, na revista "A Ordem".

\title{
A Igreja Católica frente ao mundo moderno e às transformações políticas no Brasil do século XIX
}

No século XIX, o avanço da secularização constituiu uma ameaça aos dogmas católicos. Este fenômeno, associado ao desenvolvimento do chamado modernismo católico que relativizava a validade dos dogmas, assim como a ideia da existência de uma religião verdadeira, ensejou o processo de romanização do catolicismo que se constituiu no aumento da centralização da estrutura e das atividades católicas em todo o mundo pela Santa Sé. O sucesso da romanização é atribuído pela literatura ao desenvolvimento de um movimento denominado ultramontanismo ${ }^{3}$.

Dentre os objetivos declarados em documentos eclesiais daquele período destacava-se o combate aos princípios do liberalismo, do racionalismo e da laicidade, dentre outros, que eram caracterizados como "erros" na encíclica Quanta Cura (PIO IX, 1864a). A posição conservadora da Igreja Católica foi explicitada com maior veemência nos pontificados de Gregório XVI, Pio IX, Leão XIII, Pio X e Pio XI (os dois últimos já no século XX).

A Encíclica Mirari-Vos (GREGÓRIO XVI, 1832) apresenta manifestações contrárias ao indiferentismo religioso, à separação entre Igreja e Estado, à fé na ciência ao invés da Igreja, ao liberalismo, ao indiferentismo religioso e à liberdade de consciência e de imprensa. Pode-se dizer que tais críticas eram atribuídas principalmente aos maçons, porém os mesmos não são nominados no documento. A alusão à maçonaria é indireta, conforme podemos apreender da passagem que segue:

\begin{abstract}
A muitas outras coisas de não pouca importância, que Nos trazem preocupados e enchem de dor, devem-se acrescer certas associações ou assembleias, as quais confederando-se com sectários de qualquer religião, simulando sentimentos de piedade e afeto para com a religião, mas na verdade possuídas inteiramente do desejo de novidades e de promover sedições em toda parte, pregam liberdades de tal jaez, suscitam perturbações nas coisas sagradas e civis, desprezando qualquer autoridade, por mais santa que seja. (GREGÓRIO XVI, 1832, p. 17).
\end{abstract}

\footnotetext{
${ }^{3}$ Alusão ao que se situa, do ponto da França, além dos Alpes. Para o catolicismo dominante neste país, o ultramontanismo expressava as posições dogmáticas de Roma, principalmente o dogma da infalibilidade papal.
} 
A encíclica Quanta Cura de 1864 definia claramente o pensamento reacionário da igreja de Roma. Nela o papa Pio IX condena o naturalismo, como tendência moderna que incentiva a laicidade do Estado e a liberdade de expressão. Combate também a tese da liberdade de culto, conforme podemos apreender da passagem que segue:

[...] com esta ideia do governo social, absolutamente falsa, não hesitam em consagrar aquela opinião errônea, em extremo perniciosa à Igreja católica e à saúde das almas, chamada por Gregório XVI, Nosso Predecessor, de feliz memória, loucura, isto é, que "a liberdade de consciências e de cultos é um direito próprio de cada homem, que todo Estado bem constituído deve proclamar e garantir como lei fundamental, e que os cidadãos têm direito à plena liberdade de manifestar suas ideias com a máxima publicidade - seja de palavra, seja por escrito, seja de outro modo qualquer -, sem que autoridade civil nem eclesiástica alguma possam reprimir em nenhuma forma". Ao sustentar afirmação tão temerária, não pensam nem consideram que com isso pregam a liberdade de perdição, e que, se se dá plena liberdade para a disputa dos homens, nunca faltará quem se atreva a resistir à Verdade, confiado na loquacidade da sabedoria humana mas Nosso Senhor Jesus Cristo mesmo ensina como a fé e a prudência cristã hão de evitar esta vaidade tão danosa. (PIO IX, 1864a, p. 3).

O mesmo documento defende o direito dos pais sobre a educação dos filhos, bem como a atuação do clero nesse sentido, e atribui ao "erro do comunismo e socialismo" a ideia segundo a qual:

[...] a sociedade doméstica deve toda sua razão de ser somente ao direito civil e que, por tanto, somente da lei civil se derivam e dependem todos os direitos dos pais sobre os filhos e, sobretudo, do direito da instrução e da educação. (PIO IX, 1864a, p. 5).

Além do fato de que tal doutrina contribui para o afastamento entre Igreja e Estado. No mesmo ano, Pio IX editou a bula Syllabus Errorum, que arrolou em oitenta pontos "os principais erros de nossa época", entre eles o regime liberal e a ideia de que o "Pontífice Romano pode e deve conciliar-se e transigir com o progresso, com o Liberalismo e com a civilização moderna". (PIO IX, 1864b, p. 80).

A Constituição Imperial de 1824 institui o beneplácito régio, um dispositivo constitucional que, na medida em que o catolicismo se constituía em religião oficial do Estado, subordinava ao poder temporal todas as ordens emanadas da Santa Sé, de modo que as mesmas precisavam da anuência do poder civil (imperador e Conselho de Estado) para terem valor legal. A existência de tal instituição ensejou o conflito entre o Estado Brasileiro e a Sé Romana durante a segunda metade do século XIX, que 
ficou conhecido como "Questão Religiosa do Império".

O episódio da suspensão do padre Almeida Martins, em janeiro de 1872 , foi o primeiro fato concreto que poderíamos considerar como precedente da Questão Religiosa. A sentença da expulsão de ordem foi dada pelo Bispo do Rio de Janeiro D. Pedro Maria de Lacerda sob o argumento de que o padre era membro da maçonaria. Na realidade, a imprensa havia noticiado um discurso proferido pelo Padre Almeida Martins numa festa da Loja Maçônica. (DERISSO, 2007, p. 29).

O fato acima decorreu da orientação da Santa Sé de expulsar da fileira do clero católico os padres maçons, orientação que não foi ratificada pelo poder civil e que, portanto, não tinha validade jurídica. A crise, porém, situa-se entre os anos de 1873, com a decretação das prisões dos bispos D. Vital, de Olinda, e D. Macedo, de Belém, por descumprirem a lei ao afastarem os maçons das direções de irmandades religiosas em suas localidades, e foi resolvida por meio de negociações entre o Roma e o Império no ano de 1875.

O conflito entre Poder Civil e Igreja no Brasil foi favorecido por um conjunto de combinações, a saber:

[...] o ultramontanismo de Pio IX; a recente perda de Roma e dos Estados Pontifícios para os liberais italianos no processo de unificação da Itália; e a renovação que vinha se processando no episcopado brasileiro por conta de nomeações de bispos ultramontanos em substituição a bispos mais inclinados às posições liberais ou alinhadas com o poder civil. (DERISSO, 2007, p. 30).

Pode-se dizer que, com o estabelecimento da República e a separação entre o Estado e a Igreja, esta última pode usufruir de uma liberdade até então desconhecida que favoreceu sua reorganização, por meio da qual ocorre o processo de romanização da Igreja Católica brasileira. E foi justamente temendo o fortalecimento da Igreja que o Governo Provisório, instituído após a Proclamação da República em 1889, tentou limitar a ação do clero, restringindo seus direitos políticos e proibindo o estabelecimento de novas ordens no Brasil; porém, tais proposições não se efetivaram no momento de definição da Constituição de 1891, de modo que nos anos que se seguiram pôde-se observar uma atitude conciliadora e de boa convivência entre governantes e o clero católico. 


\section{Da Primeira República à Revolução de Trinta: política e educação}

Durante a Primeira República (1889 A 1930), as principais instituições do Estado brasileiro eram dominadas pelas oligarquias rurais, cujo domínio decorria de uma economia predominantemente voltada para a exportação de gêneros primários, principalmente o café. Durante a Primeira Guerra Mundial ocorre o aumento da produção industrial motivada pela necessidade de substituição das importações que o Brasil não conseguia realizar em função da economia de guerra que orientava a produção europeia, o que implicou em novas formas de divisão do trabalho e de organização social, trazendo consequências para a situação política, que passa a sofrer a pressão da nascente classe operária e suas greves, e, sobretudo, dos setores médios urbanos, com destaque para os jovens oficiais militares e suas rebeliões. Soma-se a isso a insatisfação das oligarquias rurais excluídas da política "café com leite" (aliança entre os cafeicultores paulistas e os criadores de gado de Minas Gerais, por meio da qual dominavam o governo central).

O novo cenário que foi sendo construído nas primeiras décadas do século $\mathrm{XX}$ levou à eclosão da Revolução de Trinta, levada a cabo por forças que expressavam segmentos de classe bastante heterogêneos, formadas pela "oligarquia regional, dissidências paulistas, camadas médias, tenentes, burguesia industrializante e mesmo oligarcas depostos" (CURY, 1984, p. 8). Tal heterogeneidade acarretará em divergências posteriores ao estabelecimento do Governo Provisório, pois a reunião genérica em torno dos ideais liberais não garantia acordo quanto ao teor dos encaminhamentos que se deram em tal âmbito.

Segundo Cury (1984), a Revolução de Trinta e os esforços de "Reconstrução Nacional" possibilitaram amplos debates, nos quais se insere a Educação, uma vez que as mudanças na estrutura econômica, social e política, bem como da mentalidade de vários setores da população, implicavam em reconversão da estrutura educacional.

A resposta à crise do regime oligárquico e aos novos contornos urbano $\mathrm{e}$ industrial que se desenvolviam no país impunha a necessidade de uma nova constituição, para tanto é convocada a eleição para uma assembleia constituinte a realizar-se no ano de 1934. Nesta, os diversos grupos envolvidos nos debates educacionais desejavam concretizar constitucionalmente a consagração de seus princípios. Tais grupos foram polarizados por católicos e renovadores liberais cujas diferenças tornam-se mais explícitas após a solicitação do Governo Provisório de 
Getúlio Vargas de sugestões para o capítulo sobre Educação da nova constituição.

Até então a Educação era privilégio da elite e, portanto, a maior parte da população não tinha acesso a ela. Em um manifesto de 1932, os renovadores liberais, denominados "Pioneiros da Educação Nova" ou ainda "escolanovista", propunham o acesso à escola para as camadas médias e populares na perspectiva da erradicação do analfabetismo, vislumbrando que "a educação para a população seria a solução para os problemas econômicos, sociais, políticos, entre outros" (NAGLE, 1985, p. 263). Para os escolanovistas, alcançar esse patamar de desenvolvimento demandava uma educação escolar "prática", para formar o cidadão de acordo com suas aptidões e a força produtiva capaz de produzir a riqueza nacional.

$\mathrm{Na}$ medida em que alguns notórios escolanovistas estudaram em instituições estrangeiras ou estudaram autores europeus e americanos vinculados ao movimento que ficou conhecido com Escola Nova, exaltavam em maior ou menor grau ideais do liberalismo, tais como individualidade e igualdade de oportunidades. Ideias essas bem sensíveis aos grupos até então alijados das decisões políticas e mais particularmente da educação escolar. Vislumbravam "a democratização do ensino, a escola do trabalho, e/ou a psicologização e a administração pedagógicas dentro da própria escola" (CURY, 1984, p. 21), propunham que o ensino elementar fosse público, gratuito e laico, assim como atribuíam ao Estado o papel de conduzir o processo de renovação educacional por eles proposto.

As oligarquias, por sua própria natureza privilegiada, preocupavam-se com a escola aberta às classes populares, pois entendiam que isso implicaria em mudanças na organização social e econômica do país que acarretariam em declínio de sua ascendência sobre o conjunto das instituições. A Igreja Católica brasileira partilhava destas preocupações e vai combater os liberais escolanovistas com os argumentos, sobretudo anticomunistas, perfilados nos documentos eclesiais que analisamos em tópico precedente.

\section{A estratégia católica e a crítica aos pioneiros no processo de elaboração da Constituição de 1934}

D. Sebastião Leme, Bispo Primaz do Brasil, foi uma figura central na elaboração da estratégia adotada pela Igreja Católica Brasileira para intervir no processo constituinte que culminou na Constituição de 1934. Nesta empresa, contou 
com o apoio fundamental da intelectualidade leiga, que no Brasil daquele contexto se organizava no Centro Don Vital e se expressava por meio da Revista A Ordem. Importante destacar que a organização da intelectualidade leiga fazia parte de uma estratégia política da Igreja Católica Romana desde o final do século XIX, que foi implementada, com maior ou menor sucesso, em vários países, cujo principal objetivo era o de fazer enfrentamento aos ideais republicanos e liberais, mas, sobretudo, ao comunismo.

Com o apoio de D. Sebastião Leme, o intelectual Jackson Figueiredo funda a revista A Ordem em 1921 e em 1922 o Centro Dom Vital. Ambos difundiam críticas contundentes à laicidade e ao liberalismo, apontando-os como responsáveis pela existência do socialismo. Tal mobilização objetiva o retorno da influência do catolicismo sobre a política em função da necessidade vislumbrada de recristianizar o país; para tanto, a reinserção do ensino religioso nas escolas públicas constituía importante passo.

Num artigo intitulado "Mobilizemo-nos", de 1932, o grupo católico defende o Decreto 19.941, que instituiu o ensino religioso facultativo nas escolas públicas, com a influência da maçonaria, dos liberais e dos protestantes. Nesse sentido, o artigo é repleto de críticas aos quarenta anos de "pedagogia republicana", que implantou o ensino laico no país. O texto também acusa o pragmatismo (laicidade) e a omnipotência do Estado (controle) como responsáveis por atentarem contra a família em benefício de uma escola pública sem Deus e sem moral.

O ensino laico é considerado pelo grupo católico um retrocesso promovido pelos republicanos de 1891, acusados de atentarem contra a tradição, imitando o pensamento das revoluções ocorridas na França. Os "Pioneiros da Educação Nova" são, por sua vez, acusados de imitarem os "pedagogos yankizados, responsáveis pelos diretórios nacionais de instrução pública" (LIMA, p. 404). John Dewey, que influenciou o pensamento de Anísio Teixeira, e Émile Durkheim, que inspirava Fernando Azevedo, têm suas ideias associadas ao socialismo.

Nos artigos analisados no decorrer da pesquisa, o fim da educação seria o de atingir a meta da perfeição para Deus. O erro da "pedagogia moderna" estaria em pensá-la como que partindo da própria natureza humana para corrigi-la. Educar constitui para os católicos um processo que evolve "a criação, direção e instrução, pelas quais uma geração de homens maduros, influi no desenvolvimento daquela que se vai formando" (VAN ACKER, 1930, p. 17). E estabelece que não é possível educar 
sem moralizar. Ressalta a necessidade de conhecer os fins educativos, como uma forma de garantir a eficácia da "moderna técnica pedagógica", pois acredita que a pedagogia está permeada pela ideia de que educar envolve apenas conhecimento científico, um intelectualismo com total descaso para a formação do caráter. Enfim, problematiza-se sobre a finalidade da educação e o modo como foi conduzida até então pela pedagogia moderna. Defende-se, no referido artigo, a ideia de que o catolicismo constitui a filosofia que norteia* a concepção integral de vida necessária à ação da educação, buscando evocar o caráter natural e histórico do catolicismo no Brasil ao afirmar que o "Brasil brasileiro" precisa ser católico, dessa forma o ensino religioso iria reatar a tradição nacional, ao que conclama o apoio dos contrários, nacionalistas e liberais, para combater os reformadores.

A solução católica para os problemas da nação consistiria em um ensino que reunisse a competência técnica com uma base filosófica "sadia", em outras palavras, os princípios morais cristãos somados aos novos métodos filosóficos.

\section{Embates políticos entre católicos e liberais no processo de elaboração da Constituição de 1934}

Antes do processo constituinte, logo após a Revolução de Trinta, a Igreja se aproxima estrategicamente do Governo de Getúlio Vargas e deste estreitamento resulta o Decreto n. ${ }^{\circ} 19.941$, de 30 de abril, que instituía o Ensino Religioso nas escolas públicas em carácter facultativo. Não era exatamente o que a Igreja Católica desejava, mas foi o acordo possível entre o padre jesuíta Leonel Franca e o ministro da educação Francisco Campos. Os pioneiros, por sua vez, criticam o decreto afirmando sua inconstitucionalidade e defendem a necessidade de uma Constituinte para discutilo.

Embora as propostas dos renovadores encontrassem receptividade no Governo, este ainda dependia do apoio católico para concretizar seu projeto de Reconstrução Nacional.

Os pioneiros percebiam a luta como forma de superar as resistências conservadoras e de interesses particularistas e reacionários que impediam o modelo social e técnico-científico de compreender a Educação e a instauração de uma democracia social. São criticados pelos católicos por sua proposta de Educação que se preocupava apenas com a vida terrena sem valorizar o papel da religião e sem 
referenciar-se na moral religiosa. De fato, os reformadores não tinham interesse em questões espirituais, seu foco estava voltado para a necessidade de adequar a Educação à sociedade industrial que começava a se constituir no Brasil.

$\mathrm{Na}$ ótica católica, conforme pudemos apreender dos documentos eclesiais anteriormente citados, positivistas, liberais, protestantes, agnósticos e maçons, entre outros, devido às suas ideias "laicistas", eram anticristãos que concorriam para acabar com a organização social vigente, pois a escola sem religião teria seus laços sociais dissolvidos pelo individualismo, e este por sua vez abriria caminho para o comunismo.

Outro motivo pelo qual o grupo católico manifestava-se contrário ao ensino público laico é o de que as famílias católicas arcavam, por meio dos impostos, com as despesas de um ensino estatal mesmo matriculando seus filhos em escolas privadas confessionais, o que constituía, aliás, a orientação da Igreja, segundo a Encíclica Divini Ilius Magistri:

[...] é proibida aos jovens católicos a frequiência de escolas acatólicas, neutras ou mistas, isto é, daquelas que são abertas indiferentemente para católicos e não católicos, sem distinção, e só pode tolerar-se tal frequiência unicamente em determinadas circunstâncias de lugar e de tempo, e sob especiais cautelas de que é juiz o Ordinário. (PIO XI, 1929, s/p).

Mais interessante seria que os pais de alunos de outros credos pedissem dispensa de seus filhos da aula de ensino religioso, pois, assim, os alunos aprenderiam a tolerância para com o outro e poderiam viver em harmonia com pontos de vista diferentes.

A cisão entre católicos e pioneiros se acentua em 1931, com a realização da IV Conferência Nacional de Educação, frente ao pedido que o Governo dirige à mesma para que elabore uma proposta para o capítulo constitucional sobre Educação. Do ponto de vista do Governo, tal solicitação constituía uma tentativa de conciliar os interesses dos dois grupos, mas a elaboração da tal proposta não foi possível dado o grau de divergências e acirramento de ânimos, de modo que durante a Conferência eclode a ruptura entre os dois grupos, resultando na publicação do "Manifesto dos Pioneiros da Educação Nova", em 1932, pelos liberais (MANIFESTO, 1932).

O grupo dos renovadores contava com a representação de "republicanos com o espírito de 1891, anticlericais, católicos liberais, representantes de outros credos, da maçonaria e mesmo de esquerda" (CURY, 1984, p.113), contanto ainda com pessoas 
que desempenhavam importante papel na burocracia estatal e consequentemente nos projetos e anteprojetos enviados à ANC (Assembleia Nacional Constituinte).

No processo constituinte, as discussões comtemplaram questões como o papel do Estado na fixação do Plano Nacional de Educação (PNE), a gratuidade do ensino, a "colaboração recíproca" entre Igreja e Estado, a livre iniciativa nas escolas particulares. Mas a maior parte dos debates esteve centrada na questão do ensino religioso.

Entre os argumentos a favor do ensino religioso nas escolas públicas figuravam os seguintes: a religião é necessária para impedir a animalização do homem; os católicos constituem a maioria da população; a laicidade não apresenta raízes históricas no país; o ensino religioso consta da legislação dos países avançados; o objetivo do ensino religioso é garantir a paz social e a salvação das almas; etc.

Por outro lado, os argumentos contrários religiosos eram: a educação religiosa não é uma tarefa do Estado, mas sim, do templo e da família; a religião não deve tentar utilizar o Estado para obter fiéis; o Estado não tem qualquer obrigação para com a religião, porque sendo este laico, o ensino também o deve ser, e a reinserção do ensino religioso constituiria num retrocesso e perturbaria o ensino científico.

Para defender seus interesses na Constituinte, a estratégia adotada pela Igreja não foi criar um partido católico. Segundo Derisso (2007), para D. Leme não havia sentido a criação de um partido católico, pois conforme seu raciocínio a palavra "católico" não corresponderia à parte, mas ao todo. A solução encontrada foi constituir a Liga Eleitoral Católica (LEC), no ano de 1932. Assim, a Igreja católica insere representantes em quase todos os partidos para defender seus interesses, sendo que seu apoio se estendia a qualquer candidato desde que o mesmo estivesse de acordo com os dez pontos da Liga. Os dez pontos da LEC eram:

$1^{\circ}$ - Promulgação da Constituição em nome de Deus.

$2^{\circ}$ - Defesa da indissolubilidade do laço matrimonial, com a assistência às famílias numerosas e reconhecimento dos efeitos civis ao casamento religioso.

$3^{\circ}$ - Incorporação legal do ensino religioso, facultativo nos programas das escolas públicas, secundárias e normais da União, do Estado e dos municípios.

$4^{\circ}$ - Regulamentação da assistência religiosa facultativa das classes armadas, prisões, hospitais, etc.

$5^{\circ}$ - Liberdade de sindicalização, de modo que os sindicatos católicos, legalmente organizados, tenham as mesmas garantias dos sindicatos neutros.

$6^{\circ}$ - Reconhecimento do serviço eclesiástico de assistência espiritual às forças armadas e às populações civis como equivalente ao serviço militar.

$7^{\circ}$ - Decretação de legislação do trabalho inspirada nos preceitos da justiça social e nos princípios de ordem cristã.

$8^{\circ}$ - Defesa dos direitos e deveres da ordem social. 
$9^{\circ}$ - Decretação da lei de garantia da ordem social contra quaisquer atividades subversivas, respeitadas as exigências das legítimas liberdades políticas e civis.

$10^{\circ}$ - Combate a toda e qualquer legislação que contrarie, expressa ou implicitamente, os princípios fundamentais da doutrina católica. (MOURA; ALMEIDA, 1997, p. 306).

Destes pontos, os candidatos que buscavam o apoio da Igreja precisavam defender pelo menos o "programa mínimo" constituído pelos pontos 2, 3 e 4 .

\section{O Resultado dos Embates}

A Constituinte desenrolou-se em mais de cem sessões até que fosse encaminhado o anteprojeto de Constituição. Apenas o item sobre Educação contou com mais de 60 emendas. Acerca do ensino religioso, o artigo 153 da Constituição de 1934 estabelecia que:

O ensino religioso será de freqüência facultativa e ministrado de acordo com os princípios da confissão religiosa do aluno, manifestada pelos pais ou responsáveis, e constituirá matéria dos horários nas escolas públicas primárias, secundárias, profissionais e normais. (BRASIL, 1934).

Evidenciamos a dimensão da conquista católica se atentarmos para o fato de que no decreto de 1931 o ensino religioso limitava-se às escolas primárias, ao passo que no texto de 1934 estendeu-se para os níveis de ensino secundário e médio, além de que a Constituição promulgada a 16 de julho de 1934 contemplou todos os dez pontos da LEC.

Apesar dos projetos relacionados à laicidade do ensino terem sido derrotados no processo constituinte, os pioneiros também conseguiram incorporar parte das suas propostas à Constituição. Aliás, desde o estabelecimento do Governo Provisório até a Constituição de 1934, lograram a criação do Ministério de Educação e Saúde Pública (MESP), do Conselho Nacional de Educação, a reorganização dos ensinos secundário e superior por meio de reformas, além da instituição e criação de universidades.

Mas a Igreja não pôde comemorar sua vitória por muito tempo, porque em 1937 ocorre o golpe do Estado Novo e com ele a outorga por Getúlio Vargas de uma nova Constituição. Vejamos como ficou o ensino religioso nesta nova carta constitucional:

Art. 133. O ensino religioso poderá ser contemplado como matéria do curso ordinário das escolas primárias, normais e secundárias. Não poderá, porém, constituir objeto de obrigação dos mestres ou 
professores, nem de freqüência compulsória por parte dos alunos (grifo nosso). (BRASIL, 1937).

Evidencia-se a diminuição de importância do ensino, que passa a ser indicado como possibilidade e não mais como obrigatoriedade para as escolas públicas.

\section{Considerações finais}

Em reação às mudanças de ordem econômica, social e política que marcaram o século XIX, a Igreja Católica inclina-se para um processo de centralização do clero a partir de Roma, movimento conhecido como romanização e ultramontanismo. Manifesta-se contrária às novas tendências políticas e filosóficas deste período, tais como liberalismo, racionalismo, naturalismo, liberdade de consciência e mais enfaticamente a laicidade. Tal posicionamento conservador é facilmente identificado nos documentos eclesiásticos do período, que se expressavam pela condenação a quaisquer tipos de correntes filosóficas adeptas da separação entre Igreja e Estado e da fé na Ciência ao invés da Igreja.

No início do século $\mathrm{XX}$, com a crise do regime oligárquico e a eclosão da revolução de Trinta, conformam-se, no contexto da eleição e elaboração da Constituição de 1934, dois grupos de interesses antagônicos, ambos alinhados com determinados segmentos das classes dominantes: um deles orientado pela ideologia liberal, em favor da paz social, estabilidade e cooperação no quadro do capitalismo industrial; o outro pela cosmovisão ética representada pela autoridade de Deus. Os católicos, representando a ala mais tradicional e conservadora, apoiando oligarcas, setores autoritários e até mesmo movimentos de inspiração fascista; em contrapartida, os liberais se aliavam aos setores progressistas da classe dominante, sobretudo a nascente burguesia industrial, mas também aos setores médios urbanos que se desenvolviam com a industrialização. A fim de alcançarem seus objetivos, ambos procuraram apresentar suas exigências como demandas de toda a nação.

Apesar de possuírem interesses antagônicos, nenhum dos grupos questionava o sistema vigente e qualquer mudança sugerida, assim como a Educação aspirada pelos mesmos concorria para a manutenção da sociedade de classes e da ordem capitalista.

Do ponto de vista do Estado, as ideias dos "Pioneiros da Escola Nova" eram relevantes na medida em que representava a possibilidade de satisfazer os interesses de vários segmentos de classe, sobretudo do setor da classe dominante que almejava a 
modernização e a industrialização. Neste sentido, a educação técnico-profissional por eles proposta era muito bem-vinda. Mas este mesmo Estado que se organizava na perspectiva da modernização e da ampliação de sua base social não podia prescindir do apoio da Igreja Católica, e por isso fez significativas concessões aos católicos que resistiam à modernização.

Acerca dos pioneiros, cabe destacar a observação de Cury (1984), segundo a qual entre os problemas desse grupo encontrava-se o "messianismo científico", reflexo de uma visão ingênua da ciência como instância acima de ideologias, com potencial de transformar a realidade nacional independente das condições econômicas e imitar o progresso dos países desenvolvidos apenas pela adoção de técnicas educacionais semelhantes. Orientação que se revelou ineficaz: prova disso é o fato de que a maioria das proposições educacionais deste grupo, que foram incorporadas pela Constituição, não avança para além da letra lei.

A Igreja se saiu vitoriosa nas votações da Constituição de 1934 e conseguiu aprovar os dez pontos da LEC. O Estado, tanto como a Igreja, desejava a manutenção da ordem econômica e social, e para tanto eram interdependentes. Já as divergências aparentemente insolúveis entre católicos e liberais, assim como entre a pedagogia católica e a pedagogia nova, diluíram-se gradativamente na medida em que a própria Igreja foi reorientando suas formas de proceder frente ao assim chamado "mundo moderno", a ponto de as posições dogmáticas que caracterizam o pensamento católico na década de 1930 serem atualmente sustentadas apenas por grupos minoritários dentro da Igreja, com características fundamentalistas.

\section{REFERÊNCIAS}

BRASIL. Constituição da República dos Estados Unidos do Brasil. Rio de Janeiro: 16 de julho de 1934. Disponível em:

<http://www.planalto.gov.br/ccivil_03/constituicao/constituicao34.htm>. Acesso em: 25 ago. 2017

BRASIL. Constituição dos Estados Unidos do. Rio de Janeiro, 10 de novembro de 1937. Disponível em:

<http://www.planalto.gov.br/ccivil_03/constituicao/constituicao37.htm>. Acesso em: 25 ago. 2017

CURY, C. R. Jamil. Ideologia e educação brasileira: católicos e liberais. $2^{\mathrm{a}}$ ed., São

Paulo: Cortez Ed., 1984. 
DERISSO, J. L. O ensino religioso na escola pública e a epistemologia dos materiais implementados nas escolas oficiais do Estado de São Paulo após a Lei no .9475/97. São Carlos: UFSCar, 2007, p. 15-52.

GREGÓRIO XVI, Papa. Carta Encíclica Mirari vos. Roma, 1832. Disponível em: $<\mathrm{http} / / / \mathrm{www}$.montfort.org.br/index.php?secao=documentos\&subsecao $=$ enciclicas\&artigo $=$ mirarivos\&lang=bra $>$. Acesso em: 28 ago 2017

LEÃO XIII, Papa. Carta Encíclica Rerum Novarum. Roma, 1891. Disponível em: <http://www.vatican.va/holy_father/leo_xiii/encyclicals/documents/hf_lxiii_enc_15051891_rerum-novarum_po.html>. Acesso em: 28 ago. 2017

MANIFESTO dos Pioneiros da Educação Nova. A Reconstrução Educacional do Brasil: Ao Povo e ao Governo. São Paulo: Companhia Editora Nacional, 1932.

LIMA, A. A. Mobilizemo-nos. A Ordem. n. 34, p. 403-406, dez. 1932.

MOURA, S. L.; ALMEIDA, S. M. G. A Igreja na Primeira República. In: FAUSTO, Boris (Org.). História Geral da Civilização Brasileira. Rio de Janeiro: Bertrand Russel, tomo III, vol. 2, 1985, p. 321-342.

NAGLE, J. Educação na Primeira República. In: FAUSTO, Boris (Org.). História Geral da Civilização Brasileira. Rio de Janeiro: Bertrand Russel, tomo III, vol. 2, 1985, p. 261-291

PIO IX, Papa. Carta Encíclica Quanta Cura, Roma, 1864a. Disponível em: <http://www.montfort.org.br/index.php?secao=documentos\&subsecao=enciclicas\&artig o=quantacura\&lang=bra $>$. Acesso em: 28 ago .2017

PIO IX, Papa. Syllabus. Roma, 1864b. Disponível em:

<http://www.montfort.org.br/bra/documentos/enciclicas/silabo/>. Acesso em: 28 ago. 2017

PIO XI, Papa. Carta-Encíclica Divini Illius Magistri. Roma, 1929. Disponível em: <http://www.vatican.va/holy_father/pius_xi/encyclicals/documents/hf_pxi_enc_31121929_divini-illius-magistri_po.html>. Acesso em: 28 ago. 2017

VAN ACKER, L. Filosofia Pedagógica. A Ordem. n. 8, p. 12-23, ago. 1930.

\section{Como referenciar este artigo}

SOUZA, Aline Christine de.; DERISSO, José Luís. O pensamento católico no contexto dos embates políticos da década de 1930 no Brasil. Revista on line de Política e Gestão Educacional, Araraquara, v.21, n.3, p. 1550-1564, 2017. ISSN: 1519-9029.

Submetido em: 18/09/2017

Aprovado em: 30/11/2017 